\title{
ANALISIS PENGARUH PERSEPSI MANFAAT, PERSEPSI KEMUDAHAN, DAN KEAMANAN TERHADAP MINAT NASABAH MENGGUNAKAN MOBILE BANKING (Studi Kasus pada PT Bank Rakyat Indonesia (Persero) Tbk Kantor Cabang Semarang Pandanaran)
}

\author{
Margaretha Oktavia Pranoto *) \\ R. Gunawan Setianegara**) \\ *) margarethaoktaviap@gmail.com
}

\begin{abstract}
This research is motivated by the phenomenon of competition in the banking industry in increasing customers interest in using mobile banking. This research aims to analyze the perceived usefulness, perceived ease of use, and security on the interest in using mobile banking at the PT Bank Rakyat Indonesia (Persero) Tbk Branch Office Semarang Pandanaran.

The purpose of this study is to describe and analyze the influence customer perceptions of the interest in using mobile banking. This research uses explanatory (explanation) with a quantitative approach, in which customers of Bank Rakyat Indonesia (BRI) branch Semarang Pandanaran as a population, whereas samples taken by 100 respondents were determined by specific criteria. Research results with the $t$ test showed that the variable perceived of usefulness, perceived ease of use and security separately (partial) significantly affects the interest in using mobile banking.

Test results also showed that the variables of perceived usefulness, perceived ease of use, and security jointly (simultaneously) significantly affects the interest in using mobile banking. The magnitude of the effect of variable perception of usefulness, perceived ease of use, and security against the interest in using mobile banking is equal to $76.5 \%$, while the rest influenced by other variables that are not addressed in this study.
\end{abstract}

Keyword: Perceived Usefulness, Perceived Ease of Use, Security, and Interest In Using Mobile Banking

*) Mahasiswa Tugas Akhir Prodi Keuangan dan Perbankan Jurusan Akuntansi Politeknik Negeri Semarang **) Dosen Jurusan Akuntansi Politeknik Negeri Semarang

\section{PENDAHULUAN}

\section{Latar Belakang Masalah}

Perkembangan teknologi informasi dan komunikasi membuat industri perbankan bersaing ketat dalam inovasi produk dan layanan elektronik perbankan. Kemampuan manajemen dalam mengadopsi teknologi baru sangat menentukan tingkat keberhasilan dalam pengembangan inovasi layanan (Gan, 2006). Banyaknya jumlah bank meningkatkan persaingan di antara perusahaan perbankan yang ada di Indonesia, sehingga perusahaan yang bergerak di bidang perbankan berupaya untuk memberi nilai lebih kepada nasabah melalui pelayanan yang sesuai dengan kebutuhan dan keinginan nasabah.

Adopsi sistem teknologi informasi terjadi pada berbagai macam saluran di dalam dunia perbankan, diantaranya Automated Teller Machine (ATM), call center, online/internet 
banking, mobile banking, telephone banking, video banking dan Direct Selling Agent (DSA). Layanan perbankan diberikan untuk mendukung kelancaran menghimpun dan menyalurkan dana, baik yang berhubungan langsung dengan kegiatan simpanan dan kredit maupun tidak langsung, diantaranya jasa setoran, jasa pembayaran, jasa transfer, jasa penagihan, jasa kredit dan debit, dan lain-lain. Dengan banyaknya pilihan saluran untuk mengakses layanan perbankan, diharapkan nasabah semakin mudah dalam menggunakan layanan perbankan.

Hal ini diduga diindikasi oleh kesadaran nasabah yang semakin tinggi terhadap manfaat yang ditawarkan, dengan sentuhan kemudahan layanan mobile banking sangat membantu dalam melakukan transaksi perbankan dengan mengedepankan mobilitas satu genggaman dimana saja dan kapan saja. Tingginya minat nasabah untuk menggunakan layanan mobile banking inilah yang mendasari perlunya dilakukan penelitian tersebut. Kesetiaan pelanggan menekankan pada proses yang diawali dengan sikap positifnya lalu ditunjukkan melalui minat perilakunya terhadap produk atau jasa (Mowen dan Minor 2002:89).

\section{Rumusan Masalah}

Berdasarkan latar belakang diatas maka masalah yang akan diangkat adalah apakah pengaruh persepsi manfaat, kemudahan, dan keamanan mempengaruhi minat nasabah menggunakan Mobile Banking (Studi Kasus pada PT Bank Rakyat Indonesia (Persero) Tbk Kantor Cabang Semarang Pandanaran).

\section{KAJIAN TEORI}

\section{Pengertian Bank}

Menurut Undang-Undang Republik Indonesia No. 10 Tahun 1998 tentang Perbankan dalam pasal 1, bank adalah badan usaha yang menghimpun dana dari masyarakat dalam bentuk kredit dan atau bentuk-bentuk lainnya dalam rangka meningkatkan taraf hidup rakyat banyak.

\section{Pengertian Nasabah}

Nasabah merupakan pihak yang menabung atau menggunakan produk yang dijual atau ditawarkan oleh bank (Kasmir, 2012:202).

\section{Teknologi Informasi}

Menurut Turban, et al. (2006:49) istilah teknologi informasi menjelaskan kumpulan sumber daya informasi perusahaan, para penggunanya serta manajemen yang menjalankannya. Dengan kata lain, teknologi informasi meliputi infrastruktur teknologi informasi (TI) serta semua sistem informasi lainnya di perusahaan.

\section{Mobile banking}

Barnes dan Corbitt (2003) berpendapat bahwa mobile banking adalah suatu saluran 
dimana nasabah berinteraksi dengan bank melalui perangkat mobile, seperti telepon selular atau Personal Digital Assistant (PDA).

\section{Persepsi}

Persepsi diawali dengan pengamatan yang melalui proses hubungan melihat, mendengar, menyentuh, merasakan dan menerima sesuatu hal yang kemudian diseleksi, diorganisasi dan diinterpretasikan informasi yang diterimannya menjadi suatu gambaran yang memiliki arti.

\section{Persepsi Manfaat}

Menurut Jogiyanto (2007:114) persepsi manfaat merupakan sejauh mana seseorang percaya bahwa menggunakan suatu teknologi akan meningkatkan kinerja dari pekerjaannya.

\section{Persepsi Kemudahan}

Persepsi kemudahan penggunaan didefinisikan sebagai sejauh mana seseorang percaya bahwa menggunakan suatu teknologi akan bebas dari usaha (Davis, 1989).

\section{Keamanan}

Menurut Budhi Rahardjo (2005) keamanan informasi adalah bagaimana kita dapat mencegah penipuan (cheating) atau paling tidak, mendeteksi adanya penipuan di sebuah sistem yang berbasis informasi, dimana informasinya sendiri tidak memiliki arti fisik.

\section{Penelitian Terdahulu}

Davis (1989) mendefinisikan persepsi kegunaan manfaat (perceived usefulness) sebagai suatu tingkatan dimana seseorang percaya bahwa penggunaan suatu teknologi tertentu akan meningkatkan prestasi kerja orang tersebut. Dalam model TAM, perceived usefulness merupakan faktor yang kuat terhadap penerimaan pengguna, adopsi, dan kebiasaan pengguna (Davis 1989; Venkatesh dan Davis, 2000). Penelitian yang dilakukan oleh Pikkarainen, et al. (2004), Widyarini (2005), Amijaya (2010) dan Munir, et al. (2013) menyatakan bahwa persepsi manfaat (perceived usefulness) berpengaruh signifikan positif terhadap minat menggunakan (intention to use).

Persepsi kemudahan penggunaan didefinisikan sebagai sejauh mana seseorang percaya bahwa menggunakan suatu teknologi akan bebas dari usaha (Davis, 1989). Maksudnya adalah bahwa jika seseorang merasa percaya bahwa sistem informasi mudah digunakan, maka dia akan menggunakannya. Perceived ease of use telah terbukti memiliki pengaruh pada minat perilaku (intention behavior) melalui dua jalur kausal: (1) efek langsung pada minat, dan (2) efek tidak langsung pada minat melalui perceived usefulness. Pengaruh langsung menunjukkan bahwa perceived ease of use bisa menjadi katalisator potensi untuk meningkatkan kemungkinan penerimaan pengguna (Kusumo, 2010). 
Penelitian yang dilakukan oleh Munir, et al. (2013) serta Amijaya (2010) menunjukkan bahwa persepsi kemudahan penggunaan memiliki pengaruh yang signifikan positif terhadap minat nasabah untuk menggunakan mobile banking. Menurut penelitian terdahulu yang dilakukan Gilaninia et al. (2011), sistem keamanan disebut sebagai perlindungan kerahasiaan dalam transaksi e-banking. keamanan dapat ditingkatkan dengan penggunaan enkripsi yang memadai, tanda tangan digital dan firewall. Dalam penelitian Dixit Neha et al. (2010), Keamanan didefinisikan sebagai probabilitas subjektif dengan konsumen percaya bahwa informasi pribadi mereka tidak akan dilihat, disimpan dan dimanipulasi oleh pihak yang tidak berkepentingan. Keamanan dapat ditingkatkan dengan penggunaan enkripsi yang memadai dan tanda tangan digital (Shahram Gilaninia, et, al., 2011).

Penelitian yang dilakukan oleh Gilaninia et al. (2011) dan Ilyas et al (2013) menunjukkan bahwa keamanan memiliki pengaruh yang signifikan positif terhadap minat nasabah untuk menggunakan mobile banking.

\section{Kerangka Pemikiran Teoritis}

Berdasarkan uraian teoritis di atas dibangun suatu model kerangka pemikiran teoritis penelitian sebagai berikut

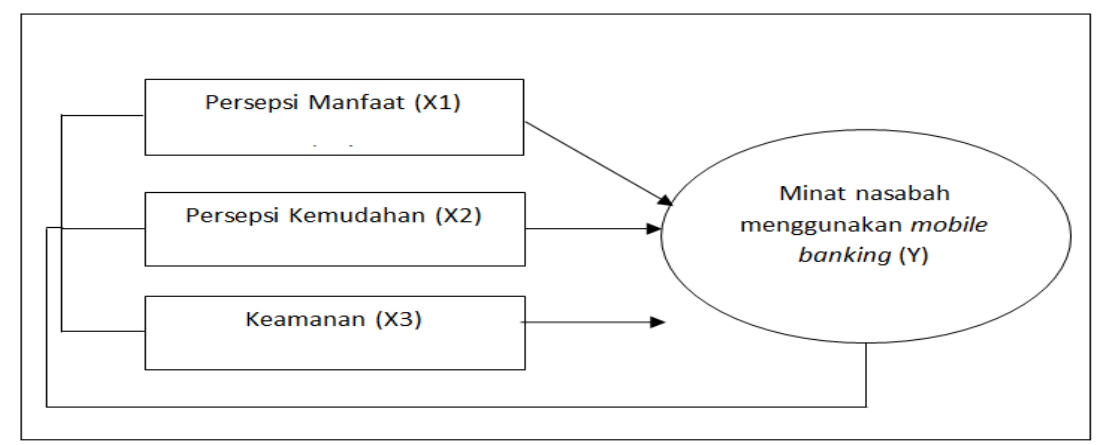

(Sumber : Ratna Purnami (2016), Giga bawa, dkk (2015), Wulandari, dkk (2017), Gilaninia et al. (2011), Imam Sugih Rahayu (2015), Laksana, dkk (2015), Davis (1989))

\section{Gambar 1 Kerangka Pikir Teoritis}

\section{METODE}

\section{Desain Penelitian}

Dalam melakukan sebuah penelitian dibutuhkan sebuah desain penelitian agar tujuan dapat tercapai dengan baik dan dapat mempermudah dalam memperoleh kesimpulan. Desain penelitian yang digunakan dalam penelitian ini adalah penelitian kuantitatif terapan kausalitas.

\section{Jenis Data}

Dalam penelitian ini jenis data yang digunakan meliputi data primer dan data sekunder. Data primer yaitu data yang diperoleh dari sumber dan bersifat mentah atau belum diolah. Data 
sekunder yaitu data yang diperoleh dari sumber yang menerbitkan dan bersifat siap pakai (Wijaya, 2013:19).

\section{Populasi dan Sampel}

Populasi dalam penelitian adalah nasabah PT Bank Rakyat Indonesia (Persero), Tbk Cabang Pandanaran Semarang yang pernah dan sedang menggunakan mobile banking. Teknik pengambilan sampel pada penelitian ini menggunakan accidental sampling. (Pengambilan sampel aksidental) yaitu menentukan sampel berdasarkan kebetulan yang ditemui atau siapapun yang dipandang cocok sebagai sumber data (Sumarni dan Wahyuni, 2006:78)

\section{Metode Analisis Data}

Menurut Wijaya (2013:57-62), analisis regresi bertujuan untuk menganalisis besarnya pengaruh variabel bebas (persepsi manfaat, persepsi kemudahan, dan keamanan) terhadap variabel terikat (minat nasabah menggunakan mobile banking). Untuk mendapatkan persamaan yang melibatkan hubungan antara lebih dari satu variabel bebas terhadap variabel terikat menggunakan regresi linier berganda. Adapun persamaan regresi linier berganda yang digunakan yaitu:

$Y=a+b_{1} X_{1}+b_{2} X_{2}+b_{3} X_{3}+e$

\section{HASIL DAN PEMBAHASAN}

\section{Hasil Uji Validitas dan Reliabilitas}

Seluruh pertanyaan dalam penelitian telah sesuai dengan kriteria hasil uji validitas. Kriteria yang digunakan untuk uji validitas adalah nilai $r$ hitung $>r$ tabel, maka hal ini berarti bahwa seluruh item pertanyaan dikatakan valid dan dapat digunakan dalam penelitian. Hasil uji reliabilitas menunjukkan, bahwa semua indikator-indikator yang digunakan untuk mengukur baik variabel independen maupun variabel dependen yang digunakan dalam penelitian ini handal sebagai tolok ukur. Hal ini terbukti dari hasil analisis reliabilitas yang menunjukkan nilai Cronbach's Alpha lebih dari 60\% atau 0,6.

\section{Hasil Uji Asumsi Klasik}

\section{Hasil Uji Normalitas}

Hasil uji normalitas menunjukkan bahwa data terdistribusi normal, yang dapat dilihat dari nilai Kolmogorov-Smirnov (K-S) yang menunjukkan nilai signifikan sebesar 0,870 lebih besar dari 0,05 . 


\section{Hasil Uji Multikolinieritas}

Hasil uji multikolonieritas menunjukkan bahwa model regresi yang dikembangkan dalam penelitian ini bebas dari gejala multikolonieritas. Hal ini ditunjukkan dengan nilai tolerance > 0,10 dari nilai VIF $<10$.

\section{Hasil Uji Heteroskedastisitas}

Hasil uji heteroskedastisitas menunjukkan bahwa model regresi yang dikembangkan dalam penelitian ini bebas dari gejala heteroskedastisitas. Hal ini ditunjukkan dari hasil uji scatterplot yang menunjukkan bahwa titik-titik scatterplot menyebar secara acak, serta tersebar baik di atas maupun di bawah angka 0 pada sumbu Y. Selain itu, hasil uji park menunjukkan bahwa semua nilai t variabel independen adalah lebih kecil dari tabel $(1,98498)$, serta hasil dari uji glejser menunjukkan bahwa nilai signifikan variabel independen adalah lebih besar dari 0,05 .

\section{Hasil Uji Autokorelasi}

Hasil uji autokorelasi menunjukkan bahwa model yang digunakan adalah model linier, yang dapat dilihat dari nilai D - W 1,724 berada di antara -2 dan +2 yang berarti tidak terdapat autokorelasi.

\section{Hasil Uji Analisis Regresi Linier Berganda}

Hasil uji estimasi model menghasilkan model regresi linier berganda sebagai berikut Minat nasabah menggunakan mobile banking $=2.622+0.726$ persepsi manfaat -0.650 persepsi kemudahan +0.528 keamanan $+\varepsilon$

\section{Hasil Uji $\mathbf{R}^{2}$ (Uji Koefisien Determinasi)}

Hasil uji $\mathrm{R}^{2}$ menujukkan koefisien determinasi (Adjusted $R$ Square) sebesar 0.765 (76,5\%). Hal ini berarti persepsi manfaat persepsi kemudahan, dan keamanan mampu menjelaskan minat nasabah menggunakan mobile banking sebesar $76.5 \%$, sedangkan sisanya sebesar $23.5 \%$ dijelaskan oleh variabel lain di luar model.

\section{Hasil Uji F}

Hasil uji F menunjukkan bahwa bahwa $F_{\text {hitung }}(108.340)>$ dari $F_{\text {tabel }}(2,7)$, hal ini berarti bahwa model memiliki goodness of fit yang baik karena persepsi manfaat, kemudahan dan keamanan berpengaruh simultan terhadap Minat Menggunakan. Selain itu hasil di atas juga menunjukkan bahwa tingkat signifikansinya sebesar $0,000<0,05$, yang berarti bahwa pengaruh simultan harga, lokasi, dan kualitas layanan terhadap keputusan menabung ulang adalah signifikan.

\section{Hasil Uji t}

Dalam tabel 1 hasil uji t menunjukkan nilai signifikansi sebagai berikut 
Tabel 1 Hasil Uji t

\begin{tabular}{|l|c|c|}
\hline Model & $\mathrm{t}$ & Sig. \\
\hline (Constant) & 2.353 & .021 \\
\hline Harga & 6.618 & .000 \\
\hline Lokasi & -3.038 & .003 \\
\hline Kualitas Layanan & 4.541 & .000 \\
\hline
\end{tabular}

Sumber: Data primer yang diolah, 2019

Hasil uji hipotesis 1 berbunyi Persepsi Manfaat berpengaruh signifikan terhadap Minat Menggunakan. Berdasarkan hasil analisis diketahui bahwa nilai $t_{\text {hitung }}>t_{\text {tabel }}(2.353>1,98498)$ dan signifikansinya di bawah 0,05 yaitu 0,001, sehingga hipotesis 1 diterima. Hipotesis 2 berbunyi Persepsi Kemudahan berpengaruh signifikan terhadap Minat Menggunakan. Berdasarkan hasil analisis diketahui bahwa nilai $t_{\text {hitung }}>t_{\text {tabel }}(6.618>1,98498)$ dan signifikansinya di bawah 0,05 yaitu 0,008, sehingga hipotesis 1 diterima. Hipotesis 3 berbunyi keamanan berpengaruh signifikan terhadap Minat Menggunakan. Berdasarkan hasil analisis diketahui bahwa nilai thitung $>t_{\text {tabel }}(-3.038>1,98498)$ dan signifikansinya di bawah 0,05 yaitu 0,000 , sehingga hipotesis 1 diterima.

\section{PENUTUP}

\section{Kesimpulan}

Berdasarkan hasil penelitian, maka dapat diambil beberapa kesimpulan yang nantinya dapat digunakan sebagai bahan pertimbangan, yaitu: (1) persepsi manfaat berpengaruh signifikan terhadap minat nasabah menggunakan mobile banking pada PT Bank Rakyat Indonesia (Persero) Tbk Cabang Semarang Pandanaran; (2) persepsi kemudahan berpengaruh negatif dan signifikan terhadap minat nasabah menggunakan mobile banking pada PT Bank Rakyat Indonesia (Persero) Tbk Cabang Semarang Pandanaran; (3) keamanan berpengaruh signifikan terhadap $\mathrm{k}$ minat nasabah menggunakan mobile banking pada PT Bank Rakyat Indonesia (Persero) Tbk Cabang Semarang Pandanaran.

\section{Saran}

Berdasarkan keseluruhan pembahasan dari hasil analisis yang telah dilakukan, maka saran yang diberikan kepada PT Bank Rakyat Indonesia (Persero) Tbk Cabang Semarang Pandanaran adalah persepsi manfaat merupakan variabel terbesar dalam mempengaruhi minat nasabah menggunakan mobile banking pada PT Bank Rakyat Indonesia (Persero) Tbk Cabang Semarang Pandanaran. Hal ini berarti, manajemen PT Bank Rakyat Indonesia (Persero) Tbk Cabang Semarang Pandanaran tetap mempertahankan atau bahkan semakin meningkatkan 
pengaruh persepsi keamanan dan kemudahan, jika hal tersebut dapat dipertahankan, maka akan meningkatkan minat nasabah menggunakan mobile banking ,sehingga dapat memaksimalkan laba perusahaan.

\section{DAFTAR PUSTAKA}

Ahmad, Pambudi, Bambang Setiyo. 2014. Pengaruh Persepsi Manfaat, Persepsi Kemudahan, Keamanan dan Ketersediaan Fitur Terhadap Minat Ulang Nasabah Bank dalam Menggunakan Internet Banking. Jurnal Studi Manajemen. Vol. 8. No. 1.

Ahmad, dkk. 2014. 2014. Pengaruh Persepsi Manfaat, Persepsi Kemudahan, Keamanan, dan Ketersediaan Fitur Terhadap Minat Ulang Nasabah Bank Dalam Menggunakan Internet Banking. Jurnal Studi Manajemen. Vol.8, No.1

Afghani, Moh. Faqih,dkk. 2016. Pengaruh Kepercayaan, Keamanan, Persepsi Risiko, serta Kesadaran Nasabah Terhadap Adopsi e-banking di Bank BRI Surabaya. Journal of Business and Banking. Vol. 6, No. 1.

Fadlan, Abi, dkk. 2018. Pengaruh Persepsi Kemudahan dan Persepsi Kegunaan Terhadap Penggunaan Mobile banking. Jurnal Administrasi Bisnis. Vol, 62. No. 1.

Ghozali, Imam. 2011. Aplikasi Analisis Multivariate dengan Program SPSS 19. Semarang: Badan Penerbit UNDIP.

Hapsara, Radityo Febri, 2015, "Pengaruh Kegunaan, Kemudahan, Resiko dan Kepercayaan Terhadap Penggunaan Mobile banking (Studi pada nasabah PT Bank Rakyat Indonesia (Persero), Tbk Kantor Cabang Solo Kartasura)" skripsi Universitas Muhammadiyah Surakarta.

Herlambang, Admaja Dwi,dkk. 2018. Minat Nasabah Dalam Menggunakan Layanan Mobile Banking. Jurnal Ilmiah Teknologi Informasi Asia. Vol. 12, No. 01

Kurniawan, David. 2013. Analisis penerimaan nasabah terhadap layanan mobile banking dengan menggunakan pendekatan Technology Acceptance Model dan Theory Of Reasoned Action. Jurnal Manajemen Pemasaran. Vol. 1, No.1

Kurniawati, Hanif Astika, dkk. 2017. Analisis Minat Penggunaan Mobile Banking Dengan Pendekatan Technology Acceptance Model (TAM) Yang Telah Dimodifikasi. e-Journal Ekonomi Bisnis dan Akuntansi. Volume IV (1) : 24-29

Laksana, Giga Bawa, dkk. 2015. Pengaruh Persepsi Kemanfaatan, Persepsi Kemudahan Penggunaan, Persepsi Resiko dan Persepsi Kesesuaian Terhadap Minat Menggunakan Mobile banking. Jurnal Administrasi Bisnis. Vol. 26. No. 2. 
Rakhmawati, Sherly, dkk. 2013. Pengaruh Kepercayaan, Persepsi Kegunaan, Persepsi Kemudahan, dan Persepsi Kenyamanan terhadap Minat Penggunaan Sistem Internet Banking Pada Nasabah Bank Muamalat Cabang Pembantu Madiun. Jurnal Akuntansi dan pendidikan. Volume 2, Nomor 2

Rahayu, Imam Sugih. 2015. Minat Nasabah Menggunakan Mobile Banking Dengan Menggunakan Kerangka Technology Acceptance Model (TAM). Jurnal Ekonomi Syariah Indonesia Volume $V$, No. 2

Wardhana, Aditya. 2015. Pengaruh Kualitas Layanan Mobile (M-Banking) Terhadap Kepuasan Nasabah di Indonesia. DeReMa Jurnal Manajemen. Vol. 10, No. 2 